dark carbonaceous colour, and greatly diminished in itze; bladder empty and contracted.

It is my opinion that, owing to the distended state of the lower part of the,colon and rectum, life was preserved, and the fatal ovent protracted, from the strong mechanical occlusion of the morbid opening, by the indurated faces, preventing thereby frecal effusion into the abdomimal carity.

\section{OPERATIONS ON THE LIPS.}

TO THE EDITOR OF THE PROVINCLL MEDICAL AND Sir, SURGICAL JOURNAT.

Through our much improved Journal, I would offer to the profession a suggestion or two for operations upori the lips, which, though not very important, seem likely to be acceptable, from their frequent applicability, the facilities they afford to the operator at the time, and satisfaction in the result.

In excisions, the hand of an assistant at each angle of the mouth, to compress the arteries, is often considerably in the way, and may be better employed. I have therefore, on the last fifteen or trenty occasions, applied, at each extremity of the lip oo be operated upon, a strong and large pair of Dieffenbach's forceps, which have effectually controlled the hæmorrhage, and left the hands of the assistant at liberty for other purposes. I have even operated without other assistance than that of the forceps. Their concave margin is towards the ear, and after applying, it is well to give them a slight pinch, to increase the compressing force. Messrs. Weiss and Co. have made them for me, and know the size and strength required.

Another trifling suggestion is the adoption of thin steel pins, instead of the usual silver ones, cutting off the points with pliers, as in operations upon the saphena.

The only other innovation I have to recommend upon the operation, is one I have practised for many years, in imitation of the veteriuary mode of producing compression and co-aptation after phlebotomy,-namely, the use of strips of lint, twisted about the pins, instead of thin liagtures. The lint should be of the firm kind, called "endless," and the strip about half an inch wide. Its value lies, of course, in the wider and more serviceable compression it gives; indeed, by two pins, with lint applied to each in a crossed form once, then two or three times tightly coiled round at the base, and tied, the whole incision is occupied, extended compression given, and the dressing completed. The lints being soaked in blood during their application, will eren adhere, after careful removal of the pins, until cicatrization is perfect.

$$
\text { I remain, Sir, }
$$

Your obedient servant, THOMAS PAGET.

Ioicester, May 15, 1848.

\section{CASES FROM PRIVATEPRACTTCE.}

'By John Richard Warideli, M.D., Edin.;

Late President of the Royal Physical and Buntenien Medical Societies, Assistant Pathologist in the Rojal Infirmary, Edinburgh, \&c. \&c.

\section{Cast VII.}

Fits during Labour:

- SREMARKS. - In offering the following remarks upon the foregoing case, it may firstly be observed, that the nomenclature employed, must needs appear to obstetricians and systematic writers less precise and definite than could have been wished; but it unfortunately happens both for those who write and their readers, that the multifarious aspects which diseases assume, their complications and the many contingent circumstances by which their ostensible phenomena are modified, that it is often no easy matter, nay, frequently very difficult, or even impossible, to refer them to the defined classes of nosological arrangements. Sometimes it is true we meet with diseases in a simple and perfectly intelligible form, when we can with confidence speak explicitly as to their real nature, but as asserted, it is often otherwise, as in the illustration now presented to the reader, in which there were certain negative and positive facts, which in my own mind, rendered it doubtful whether the case could or could not be considered as one of puerperal convulsions, - that is according to the generally received notions of the term, unless we receive the subdivisions of certain authors who have made a classification of it during the puerperal state, some of which classes describe the affection as very different to others. It was under this incertitude that I have employed the appellation as above.

Such other cases of puerperal convulsions as have come under my notice, and were real puerperal convulsions of an alarming character, are in many respects diverse to the one described here. In the former the muscular agitation was much greater, there was tossing about of the head, biting of the tongue, foaming at the mouth, stertor, a full strong, labouring pulse, and heat of surface ; in the latter, as we have seen, there was no foaming, a quiescent rigidity more than a convulsive action of the muscular system, no rattling during respiration, a cold surface, small slow and compressible pulse, with lachrymation, dilated pupils, etc., rendering the symptoms of a highly hysterical nature. "Dewees," says Ramsbotham in a foot-note in his work, "classes puerperal convulsions under three heads - epileptic, apoplectic, and hysteric Baudeloque arranges them under the titles of tetanus, epilepsy, and catalepsy. Merriman styles them dystocia epileptica; while Velpean and Desormeau prefer the general term eclampsia." The first paroxysm was perhaps somewhat more of a convulsive character than those which followed, most probably owing to the 
rreater irritation given to the system by the continued eiforts of expulsion, and speaking from my limited experience of what $I$ have observed in the grave forms of the affection, the attacks coming on after the birth of the child, were less severe than those previous to delivery, a fact which 1 believe as a general rule bolds good.

Those who have seen much of the diseases of females are aware that we sometimes see bysteria and epilepsy combined, there being indubitable characteristics : of each affection, inextricably blended, and in the instance of this girl, a review of the case must needs convince the reader that the syraptoms of hysteria were considerably mixed up with her affection. I now, though several years have passed away, recollect an instance of the kind which occurred in the wards of the Edinburgh Infirmary, during the time that I was clinical clerk to the late Professor Graham. It was a true compound of hysteria and epilepsy, 80 much 80 as to render it a matter of considerable doubt as to which of the names could most properly be adopted. In the case-book of the hospital I had described it as more particularly being considered epilepsy; the Professor, however, at his visit, said that although it very nearly simulated that form in several features, it laid an equal claim to Protean hysteria. It is cases like these which throw out insuperable difficulties to systematizers and medical commentators, that pre. clnde exactitude of opinion as to diagnostic conclusions, and often render treatment at least but doubtful. It would indeed be Utopian to suppose that our art will ever become so far perfected, as to completely clear away all these and many kindred difficulties which' so mystify the science of medicine; yet it is to be hoped that a narrow scrutiny of the phenomena of disease-the greater attention which is now generally paid to cause rather than effect-and the more philosophical notions which obtain in the schools, and in the profession in general, will ultimately tend in an important manner to ensure results, whereby our notions will become of a definite character, and consequently with more clearness, point out the mode of cure.

Referring to the above report of the case, we see 'that the os uteri, with an unaccustomed suddenness, (in a primiparous female,) became dilated. The first fit was just at the time when the os was about to acquire its full expansion, immediately before the termination of the first stage, - a circumstance worthy of some notice, as all obstetric writers agree that puerperal fits by far more commonly supervene, shortly before the entire dilatation of the womb, and which is previously mentioned when remarking upon the intance of Ann W-_, in No. IIr. of this series. Agaip, the parts being so cool, did not lead to the "ippocition that any nutoward event would occur. The pelvic entios wen pot by any means contracted, the presentation was natural, the pains came on at regular intervals, the patient did not complain of any head affection, and altogether it was fair to prononnce that the delivery would be one of the most favourable. description.

The reader, on returning to Case No. III. will, in the observations there offered, find that certain authorities have considered the causes of puerperal convulsions as divisible into centric and excentric,-that is, certain morbid conditions existing in the brain and spinal marrow themselves, or a source of irritation applied to the sentient nerrous extremities, which irritative impression wonld of course be conveyed to the central organs by the afferent nerves properly so called. Now, in this instance, the bowels bad long been irregular; a week before parturition there had been considerable constipation, and we are distinctly told in the report, that at the time of her delivery there was diarrbca, a condition undoubtedly that was calculated to act as an excitant; and when we also take into account the long disordered state of the bowels, the irritative matters thus collected;-also that this was illegitimate birth-that it was a first birth-that the consciousness of error, the loss of self respect, forfeiting perhaps the friendship and esteem of friends by which the mind could not fail to become in some degree perturbated; there were physical and moral causes, calculated to disorder the nervous system, and thus constitute a first cause, for the derelopment of this kind of affection.

Professor Simpson has recently given to the profession some new views relatire to the radical pathology of puerperal convulsions, but certain of the conclusions at which he has arrived appear invested with some degree of doubt, nor can such be implicitly received before more extensive data have been amassed elucidatory of the subject. Medical facts, as they are termed, ought ever to be tardily accepted, and not before ample corroborations have been made by others, or there would be a dauger of new doctrines, and those blended with error, being subscribed to, to the prejudice of more confirmed, though opposed, opinions. It is true that a vitiated condition of the blood, which disease of the kidneys must in some measure produce, might by disordering the system generally predispose to the affection in question; but it might be asked why should the convulsions become manifest precisely at the time of parturition, seeing that the cause had been long existent? Why not as likely before or afterwards? Again, convulsions do supervene when not the slightest disease of the kidneys is present, not even functional disorder. In the instance of the girl Shaffell, (if we are to consider her's as a mild modification of puerperal convulsions, the urine upon being carefully. tested was in a perfectly bealthy condition. The inquination of the blood which Dr. Simpson opines as the manner in which the nerrous system becomes 
disordered, and thus rendered in a state highly predisponent to cunvulsire action, must be from the absorption of urea, a salt which in health passes off in the urine, and which possesses those deleterions effete matters that are positirely poisonous, and cannot be retained in the circulation without exerting a noxious influence: upon the entire animal economy, and if continued must needs usher in a fatal termination. Now, " in several specimens of the blood of patients suffering. nder severe puerperal convulsions, furnished by $\mathrm{Dr}$. Simpson to Dr. Christison and Dr. Douglas Maclagan, these gentlemen had been unable to detect any traces of urea," which of course supplies a negative fact, casting doubt upon Dr. Simpson's theory. I have but little dubiousness in my own mind, that death in typhus ferer in many cases is positively poisoning by the presence of urea in the blood, and that if the proper remedies had been used many a life might have been sared. I will not here, howerer, enter into the details of that theory, which has been freely discussed in another place ;* yet this may be said, that in those, instances which $I$ have seen all but lost, when ureal" symptoms were recognized, and gfterwards the salt produced abundantly from the blood, convulsions were not the prominent symptoms-the condition of narcotism was present, and the effects produced were those of a general depression of vital power. Albuminuria, it is true, by creating a general disorder in the body, might make convulsions in some measure liable to come on, but to say that it constitutes a specific cause, is still dubious, nor can that conclusion, although emanating from so respectable an authority, be yet implicitly adopted. It cannot be denied that the most frequent ascertainable causes of puerperal convulsions are constituted by extrinsic irritation, as that produced by dyspepsia, affections of the liver, the accumulation of scybalous and acrid matters in the bowels, disease of the digestive mucous surface, of the uterus or its appendages, mobility of the nervous system, and a depressed condition of the mind.

If the reader will compare this case with No. III., he will see that the symptoms of the one depmanded a line of treatment differing from that of the other. In the instance of Ann W-, actire and copious depletion was without any hesitation the rational mode of procedure, and indeed this is indisputable when it is considered that in her case fifty ounces of blood were drawn, with the most signal benefit within three hours. But let us ask, what were the conditions demanding such energy? There was a hot skin, violent convulsive agitation, with a pulse large, quick, labouring, and strong; the eyes looked fierce and starting, and from the intense facial congestion the brain was manifestly in state of considerable congestion. With Shaffell were rery opposite states; the surface was cool, even

- Stee a ceries of papers "On Fever"by the writer of this artible, in the Medical Gaseite, for the jears 1846 and 1847. helow par; the pulse, though immediately, after, the supervention of the first fit of tolerable strength, rapidly became small, weak, slow, and compressible ; the facial congestion was less formidable ; in fine, her case was one indicating stimulation, one in which the vital powers required rousing, and such the treatment fully verified. In the treatment of Ann W-, I was from a fall conviction of its efficacy led to lay much stress upon the prompt and very. fearless use of the lancet; and in another instance, if the same phenomena were present, I should undoubtedly observe the same mode of cure; but to have done the same in the instance of Shaffell, would have been acting in opposition to scientific as well as common sense principles, nor could such have possibly been attended with any felicitous results. It is these complicating conditions in diseases of apparently a similar nature that cast such incertitude on the line of cure to be pursued, and that can only be determined upon at the moment when our aid is required. Trite rules in medicine can never with safety be in a undeviating manner observed, and we must rather base our measures upon deductive inferences, founded upon general principles, than blindly adhere to the trammels of the schoolmen.

The great use of the voltaic electricity in this case was extremely manifest, and it may confidently be asserted, that this remedy will every day come more into general use. Its virtues in many cases, particularly in nervous diseases, are beyond dispute, and have long been acknowledged, though not employed to that extent, which as a medicinal measure with advantage it night have been. Though an agent of inanimate nature, philosophical investigations have abundantly proved that the so-called nerrous influence is in many appreciable characteristics precisely similar; bence, when the nerrous influence in our bodies is deficient or impaired, to supply this agent appears rational and philosophic. We have seen that in this case its application by rousing the central organs was immediately followed by the most perceptible effect produced in the vascular system, and that with such effect the unfarourable symptoms were removed.

Straton Villa, Acacis Road, Regent's Park.

(To be continued.)

\section{T2ospital Reports.}

\section{WEST NORFOLK AND LYNN HOSPITAL.}

COMPLICATED SURGICAL CASES UNDER THE CARE OF CHARLES COTTON, ESQ., M.D., F.1R.C.S.,

RESECTION OF THE RLBOW : SUBSEQUENT AMPUTATION OF THE UPPER ARY.

Isabella Bolton, aged 24 years, admitted February 7th, 1847, with disease of left elbow, of twelve wonths" atanding. Had two years before been a patien in the hoppital for disease of the same. joint, which yielded 